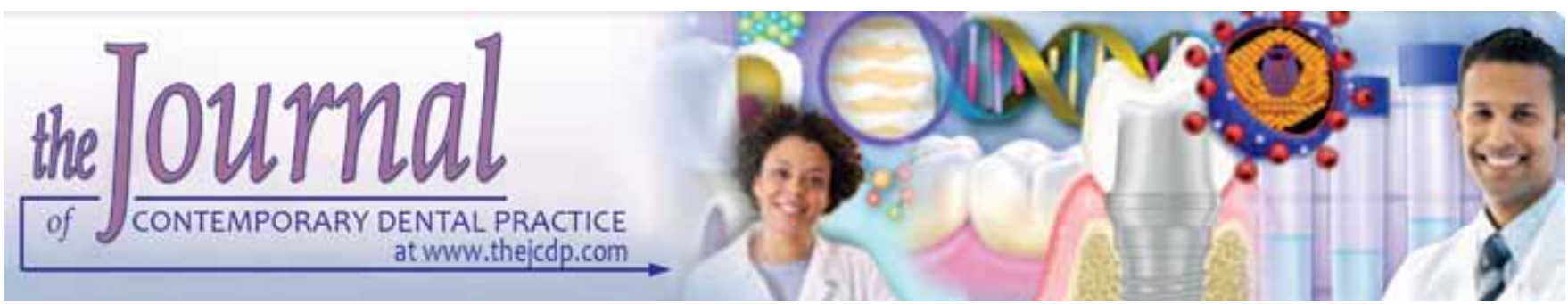

\title{
Biomarkers of Orthodontic Tooth Movement in Gingival Crevicular Fluid: A Systematic Review
}

\author{
Adel M Alhadlaq
}

\begin{abstract}
Background: The analysis of gingival crevicular fluid (GCF) may be an acceptable way to examine the ongoing biochemical processes associated with bone turnover during orthodontic tooth movement. If it is possible to biologically monitor and predict the outcome of orthodontic forces, then the management of appliances could be based on individual tissue responses, and the effectiveness of the treatment could be improved.
\end{abstract}

Methodology: A literature search was carried out in major databases, such as medline, EMBASE, cochrane library, web of science, google scholar and scopus for relevant studies. Publications in English between 2000 and 2014 which estimated GCF markers as indicators of orthodontic tooth movement were included.

Results: The list of biomarkers available to date was compiled and presented in table format. Each biomarker is discussed separately based on the available evidence.

Conclusion: Several sensitive GCF markers are available to detect the biomechanical changes occurring during orthodontic tooth movement. Further focused research might help to analyze the sensitivity and reliability of these indicators, which in turn can lead to the development of chairside tests to assess the outcome of orthodontic therapy.

Keywords: Biomarkers, Biomechanical therapy, Gingival crevicular fluid, Orthodontic tooth movement, Prognosis.

How to cite this article: Alhadlaq AM. Biomarkers of Orthodontic Tooth Movement in Gingival Crevicular Fluid: A Systematic Review. J Contemp Dent Pract 2015;16(7):578-587.

Source of support: Nil

Conflict of interest: None

Department of Pediatric Dentistry and Orthodontics, College of Dentistry, King Saud University, Riyadh, Saudi Arabia

Corresponding Author: Adel M Alhadlaq, Associate Professor Department of Pediatric Dentistry and Orthodontics College of Dentistry, King Saud University, P.O. Box No. 60169 Riyadh-11545, Saudi Arabia, e-mail: aalhadlaq@hotmail.com

\section{INTRODUCTION}

The events leading to orthodontic tooth movement are complex and include interactions between the alveolar bone cells and periodontal ligament (PDL) cells, along with multiple intercellular actions. The tooth displacement and remodeling activities are a consequence of an inflammatory process induced by mechanical stimuli. The cellular, biochemical and molecular events that occur during orthodontic tooth movement have been extensively studied. During orthodontic treatment, the forces exerted on the tooth distort the PDL's extracellular matrix and alter the cellular shape and cytoskeletal configurations. These changes may modify the flow rate and composition of the gingival crevicular fluid (GCF). ${ }^{1}$ Analysis of GCF samples may provide a better understanding of the biochemical processes associated with tooth movement.

Mechanical stimulation causes an inflammatory reaction within the periodontal tissues, which in turn, may trigger the biological processes associated with bone remodeling. Force application disrupts the equilibrium that exists between bone formation and resorption, resulting in more bone resorption than formation on the pressure side and more bone formation than resorption on the tension side. With orthodontic intervention, prolonged pressure on the teeth results in enhanced remodeling of periodontal structures, including supracrestal gingival and PDL fibers, as well as the alveolar bone. ${ }^{2}$ Orthodontic movement promotes remodeling of the alveolar bone, which is mediated by inflammatory-like reactions characterized by vascular changes and infiltration of leukocytes. ${ }^{3,4}$ During orthodontic movement, changes in the periodontium occur, depending on the magnitude, direction, and duration of the applied force. ${ }^{5}$

Resorption of bone by osteoclasts is coupled with subsequent bone formation by osteoblasts. Local and systemic factors, including cytokines, hormones, growth 
factors, and mechanical stimulation activate osteoblasts to produce osteoprotegerin ligand, which is vital for osteoclast differentiation and activity. Osteoblasts also regulate mature osteoclasts downstream of the osteoprotegerin ligand in other ways, including through interstitial collagenase activity. ${ }^{6}$ During bone remodeling, components of the extracellular matrix, such as collagen, are degraded and removed, and new components are synthesized and deposited. The efficiency of orthodontic treatment is attributed to the outcome of various mechanics employed for tooth movement. An understanding of the array of biological events that underlie tooth movement is essential for the clinician. ${ }^{1,7}$

The GCF is a complex mixture of substances derived from serum, host inflammatory cells, structural cells of the periodontium, and oral bacteria. It arises from the gingival plexus of blood vessels in the gingival corium, subjacent to the epithelial lining of the dentogingival space. The GCF can be isolated from the healthy sulcus, although only in small amounts. In a healthy periodontium, GCF represents the transudate of gingival tissue interstitial fluid produced by an osmotic gradient that tends to increase in volume with inflammation and greater capillary permeability. ${ }^{8}$ The components found in the GCF originate from the blood, host tissues, and subgingival plaque. ${ }^{9}$ The molecules isolated from the sulcular fluid include electrolytes, small organic molecules, proteins, cytokines, specific antibodies, bacterial antigens, and enzymes of both host and bacterial origin. The GCF was initially considered to be a continuous transudate, but it is currently considered to be an inflammatory one. ${ }^{10}$

The host-derived substances in the GCF include antibodies, cytokines, enzymes and tissue degradation products. During inflammatory conditions, such as gingivitis and periodontal disease, the inflammatory exudate increases by more than 5 -fold. ${ }^{11}$ Nearly half of the cells in the GCF are leukocytes; thus, the major route of entry of these cells into the oral cavity is through the gingival sulcus. These inflammatory cells persistently emigrate from the peripheral blood stream into the gingival sulcus due to chemotactic factors initiated by inflammation. ${ }^{9}$ Orthodontic forces produce an environment that can be described as 'a continuous sequence of inflammation and repair designed to restore normal tissue continuity and function. ${ }^{12}$ It has been observed that markers of bone remodeling and destruction can also be found in GCF. Therefore, it has been shown that GCF may reflect the immune and inflammatory reactions arising from both periodontitis and the application of orthodontic force. ${ }^{13,14}$

The tooth-supporting tissues are constantly remodeled under normal conditions with physiological tooth migration. Mechanical stimuli cause an inflammatory reaction within the periodontal tissues, which in turn may trigger the biological processes associated with bone remodeling. With orthodontic intervention, prolonged pressure on the teeth results in enhanced remodeling of periodontal structures, including supracrestal gingival and PDL fibers, as well as alveolar bone. ${ }^{2}$

The measurement of biological markers in the GCF and their association with clinical outcomes can be useful for monitoring and predicting the outcome of orthodontic treatment. The effectiveness of treatment can also be improved based on individual tissue responses. The longitudinal effect of different force delivery systems on tooth movement can be investigated by evaluating biochemical changes in the GCF. Thus, GCF analysis may provide a noninvasive method, allowing the modification of retention procedures after orthodontic treatment because of the unpredictable nature and extent of posttreatment relapse following retention. The objective of this systematic review is to critically evaluate the GCF markers related to orthodontic tooth movement reported in the literature.

\section{METHODOLOGY}

\section{Search Strategy}

The search intended to address the question 'Do variations in the GCF components reflect orthodontic tooth movement?' The focused question was developed as per the patient, intervention, comparison, and outcome (PICO) format. ${ }^{15}$ Two investigators independently searched the medline, EMBASE, cochrane library, web of science, google scholar, and scopus databases for relevant studies. The search was carried out using a combined text and MeSH search strategy; using the keywords 'gingival crevicular fluid' and 'orthodontic' and/or 'biomarker' or 'tooth movement'. Publications in English between 2000 and 2014 that estimated GCF components as markers in the diagnosis and assessed the severity or responses to treatment were included. Due to the large number of markers used and the lack of a sufficient number of studies dealing with each marker, the accuracy and predictability of the markers were not considered in this systematic review. The markers are listed in Table 1 with relevant references.

\section{Study Selection Criteria}

Studies reporting an association between orthodontic tooth movement and alterations in the components in GCF were included. The types of studies included were: cross-sectional, experimental and interventional 
Table 1: Gingival crevicular fluid biomarkers in orthodontic tooth movement

\begin{tabular}{|c|c|}
\hline \multicolumn{2}{|l|}{ Proinflammatory mediators } \\
\hline $\mathrm{IFN}-\gamma$ & Grant et al ${ }^{86}$ \\
\hline $\mathrm{IL}-1 \beta$ & $\begin{array}{l}\text { Atug Ozcan et al, }{ }^{87} \text { Rody et al, }{ }^{57} \text { Grant et al, }{ }^{86} \text { Ribagin et al, }{ }^{25} \text { Luppanapornlarp et al }{ }^{80} \text {, } \\
\text { Tzannetou et al }{ }^{26} \text {, Ren et al, }{ }^{13} \text { Iwasaki et al, }{ }^{88} \text { Basaran et al }{ }^{82} \text { Giannopoulou et al, }{ }^{61} \text { Yamaguchi } \\
\text { et al }{ }^{63} \text {, Dudic et al, }{ }^{62} \text { Iwasaki et al, }{ }^{56} \text { Lee et al },{ }^{30} \text { Iwasaki et al, }{ }^{89} \text { Iwasaki et al }{ }^{19}\end{array}$ \\
\hline IL-2 & Basaran et $a^{82}$ \\
\hline IL-6 & van Gastel et al, ${ }^{90}$ Ren et al, ${ }^{13}$ Basaran et al, ${ }^{82}$ Ren et al, ${ }^{14}$ Grant et al ${ }^{86}$ \\
\hline IL-8 & van Gastel et al, ${ }^{90}$ Grant et al, ${ }^{86}$ Ren et al, ${ }^{13}$ Basaran et al, ${ }^{82}$ Tuncer et al ${ }^{81}$ \\
\hline TNF- $\alpha$ & Grant et al, ${ }^{86}$ Karacay et $\mathrm{al}^{5}$, Ren et al, ${ }^{13}$ Basaran et al ${ }^{82}$ \\
\hline \multicolumn{2}{|l|}{ Anti-inflammatory mediators } \\
\hline IL-1RA & Rody et al ${ }^{57}$ Iwasaki et al, ${ }^{88}$ Iwasaki et al, ${ }^{56}$ Iwasaki et al, ${ }^{89}$ Iwasaki et al ${ }^{19}$ \\
\hline TGF- $\beta 1$ & Barbieri et al ${ }^{69}$ \\
\hline \multicolumn{2}{|l|}{ Hormones } \\
\hline Leptin & Dilsiz et $a^{59}$ \\
\hline PGE2 & Dudic et al, ${ }^{62}$ Giannopoulou et al, ${ }^{61}$ Lee et al, ${ }^{30}$ Ren et al ${ }^{14}$ \\
\hline IGFBP-3 , IGF-1 & Toia et $\mathrm{al}^{60}$ \\
\hline \multicolumn{2}{|l|}{ Enzymes } \\
\hline ALP & Abdul Wahab et al, ${ }^{51}$ Abdullah et al, ${ }^{91}$ Batra et al,,${ }^{92}$ Perinetti et al ${ }^{52}$ \\
\hline AST & Abdul Wahab et al ${ }^{51}$ Perinetti et al ${ }^{52}$ \\
\hline $\mathrm{LDH}$ & Abdul Wahab et al, ${ }^{51}$ Perinetti et al, ${ }^{76}$ Serra et al, ${ }^{44}$ Alfaqeeh and Anil ${ }^{45}$ \\
\hline$\beta-G$ & Tzannetou et $a^{26}$ \\
\hline $\mathrm{CAB}$ & Rhee et al, ${ }^{54}$ Sugiyama et al ${ }^{53}$ \\
\hline MMP-1, MMP-2, MMP-13 & Bildt et $\mathrm{al}^{83}$ \\
\hline MMP-3 & Capelli J et al ${ }^{85}$ \\
\hline MMP-8 & Apajalahti et al, ${ }^{49}$ Ingman et al, ${ }^{3}$ Ribagin and Rashkova ${ }^{25}$ \\
\hline MMP-9 & Grant et al, ${ }^{86}$ Bildt et al ${ }^{83}$ \\
\hline TIMP-1, TIMP-2 & Grant et al, ${ }^{86}$ Bildt et al ${ }^{83}$ \\
\hline \multicolumn{2}{|l|}{ Bone biomarkers } \\
\hline OPG & $\begin{array}{l}\text { Rody et al, }{ }^{57} \text { Tuncer et al, }{ }^{81} \text { Grant et al, }{ }^{86} \text { Barbieri et al, }{ }^{69} \text { Kawasaki et al, }{ }^{40} \text { Toygar et al, }{ }^{93} \\
\text { Nishijima et al }{ }^{39}\end{array}$ \\
\hline RANKL & Rody et al, ${ }^{57}$ Grant et al, ${ }^{86}$ Kawasaki et al, ${ }^{40}$ Nishijima et al, ${ }^{39}$ Kuroki et al ${ }^{94}$ \\
\hline RANK & Barbieri et al ${ }^{69}$ \\
\hline Osteocalcin & Alfaqeeh and Anil ${ }^{95}$ \\
\hline \multicolumn{2}{|l|}{ Others } \\
\hline Substance P & Giannopoulou et al, ${ }^{61}$ Dudic et al, ${ }^{62}$ Yamaguchi et al ${ }^{63}$ \\
\hline GM-CSF & Grant et al, ${ }^{86}$ Ren et al ${ }^{14}$ \\
\hline PTX-3 & Surlin et $\mathrm{al}^{64}$ \\
\hline
\end{tabular}

IFN $\gamma$ : Interferon $\gamma$; RANKL: receptor activator of nuclear factor kappa-B ligand; RANK: receptor activator of nuclear factor kappa-B; IL: interleukin; IL-1RA: interleukin receptor antagonist; MMP: matrix metalloproteinases; TIMP: tissue inhibitor of metalloproteinases; TNF- $\alpha$ : tumor necrosis factor alpha; PGE2: Prostaglandin-E2; ALP: Alakaline Phosphatase; AST: Aspartate aminotransferase; LDH: Lactate Dehydrogenase; $\beta G$ : Beta-glucuronidase; CAB: cathepsin B; GM-CSF: granulocyte-macrophage colony-stimulating factor; PTX3: Pentraxin-3; OPG: Osteoprotegerin; TGFB1: Transforming growth factor B1; IGF1: Insulin-like growth factor-I; IGFBP-3: Insulin-like growth factor-binding protein 3

studies. Patients in all age groups were included. Studies presented solely in the form of abstracts in scientific conferences and studies published in languages other than English were not considered in this review.

\section{Interleukins}

Interleukins (ILs) represent one of the proinflammatory cytokines released from many cell types, such as fibroblasts, osteoclasts, and polymorphonuclear leukocytes (PMNs). The time-related production of regulatory proteins or proinflammatory cytokines, such as interleukins that are involved in the periodontal remodeling processes is provoked by orthodontic stimuli. ${ }^{16}$ The study of interleukins as biomarkers to understand the cellular metabolic reactions involved in orthodontic tooth movement has been considered mainly due to their role in the normal physiologic turnover of bone as well as remodeling processes associated with the application of mechanical stress. ${ }^{17-20}$ The IL-1, IL-6 and IL- 8 are proinflammatory interleukins, that have been identified in the GCF during orthodontic tooth movement. ${ }^{21}$ Interleukin-1, a cytokine with proinflammatory effect and a potent stimulator of bone resorption, is produced by activated macrophages, monocytes, B-cells, neutrophils, fibroblasts, and epithelial 
cells. It is involved in the proinflammatory process, matrix degradation, and wound healing. ${ }^{22}$

Interleukin- 8 is produced and secreted by many cells, such as fibroblasts, epithelial cells, endothelial cells and alveolar macrophages, in response to inflammation. It is a potent proinflammatory cytokine that plays an important role in the recruitment and activation of neutrophils during inflammation. Therefore, neutrophils and other inflammatory cells migrate out of PDL capillaries to the inflammatory region. Interleukin-6 is a macrophage and T-cell originating cytokine. The healing of periodontal pockets may be affected by an accumulation of IL- 6 in the adjacent connective tissue as a result of increased synthesis or reduced release into the GCF. ${ }^{23}$ Studies have shown that IL-1 $\beta$ can stimulate bone resorption during orthodontic tooth movement. ${ }^{24-26}$

\section{Tumor Necrosis Factor- $\alpha$}

Tumor necrosis factor- $\alpha$ (TNF- $\alpha$ ) is a monocyte/ macrophage-derived proinflammatory cytokine that can stimulate proteolytic enzyme synthesis and osteoclast activity. It is another proinflammatory cytokine that has been investigated in orthodontic tooth movement and is involved in bone resorption and both acute and chronic inflammation. Tumor necrosis factor- $\alpha$ is produced primarily by activated monocytes and macrophages and by osteoblasts, epithelial cells, and endothelial cells. ${ }^{27}$ It is also an apoptotic factor for osteocytes, which could be the signal for osteoclast recruitment to resorb bone in the side undergoing PDL pressure, while simultaneously inhibiting osteoblasts. ${ }^{28}$

\section{Prostaglandin E2}

Prostaglandin E2 (PGE2) is a metabolite of arachidonic acid and a potent biochemical mediator of inflammation, with many proinflammatory effects. It has been reported to act as a biochemical mediator of bone resorption induced by orthodontic tooth movement. Orthodontic force applied to the tooth stimulates the localized cells to synthesize and secrete PGE2, which, in turn, stimulates osteoclastic bone resorption. ${ }^{29}$ Prostaglandin E2 is known to be a potent stimulator of bone resorption and its production is controlled in part by IL-1. Studies have shown that the level of PGE2 in human GCF was highest 24 hours after the mechanical force was applied and decreased to the baseline within 7 days. ${ }^{24,30}$

\section{Glycosaminoglycans}

Glycosaminoglycans (GAGs) are found in the extracellular matrix of mineralized and other connective tissues and are negatively charged complex carbohydrates that are linked covalently in the native state to a core protein to form proteoglycans. ${ }^{31}$ The changes in GCF-GAGs during and after orthodontic treatment have been investigated. ${ }^{31}$ The change in a GAG component, chondroitin sulfate, was related to the duration of retention, while the increase in GCF volume during orthodontic movement and the decrease during retention were related to changes in the severity of gingival inflammation. The GAGs in human GCF during orthodontic movement were also studied by Last et al. ${ }^{32}$ They concluded that the GAG composition of GCF, particularly chondroitin sulfate, appears to reflect changes that occur in the deeper periodontal tissues of alveolar bone and PDL orthodontic treatment. Samuels et al showed varying GAG levels with different types of orthodontic tooth movement in a study of GCF during orthodontic treatment. ${ }^{33}$ The level of chondroitin sulfate, in particular, could be a potential marker to be monitored during orthodontic tooth movement.

\section{Granulocyte Macrophage Colony Stimulating Factor}

Granulocyte macrophage colony stimulating factor (GMCSF) and vascular endothelial growth factor (VEGF) can induce osteoclast recruitment. They are considered to be closely involved with the bone remodeling process. An increase in both VEGF and GM-CSF concentrations in the GCF during canine retraction has been reported. ${ }^{34}$ These factors may induce bone remodeling via osteoclastic bone resorption.

\section{Osteocalcin}

Osteocalcin (OC) is a non-collagenous matrix protein and is a major component of bone extracellular matrix. ${ }^{35}$ It is produced by osteoblasts and has been described as the most specific marker of osteoblastic function. ${ }^{36}$ Structurally, it binds to both major bone components (collagen and apatite), and is believed to play a role in both-bone resorption and mineralization. The GCF-OC is considered a marker for bone turnover originating during bone formation as well as bone resorption. Osteocalcin has been found in the GCF from patients with periodontal disease, and increases in GCF's OC concentration have been associated with high rates of bone turnover through the enhancement of osteoclastogenesis. ${ }^{37,38}$

\section{Receptor Activator of Nuclear Factor Kappa-B, Osteoprotegerin and Receptor Activator of Nuclear Factor Kappa-B Ligand}

Receptor activator of nuclear factor kappa-B (RANK) is known to stimulate osteoclastic generation from precursor cells. The role of RANK and its receptors, 
namely osteoprotegerin (OPG) and receptor activator of nuclear factor kappa-B ligand (RANKL), is very crucial in the bone remodeling process. During orthodontic tooth movement, RANKL has been implicated in the pressureinduced generation and maintenance of osteoclasts by binding to RANK. Osteoprotegerin is a decoy receptor produced from the osteoblastic lineage that prevents the maturation of osteoclasts and apoptosis with RANK for RANKL. An increase in the 'RANKL-RANK' level and a decrease in OPG level were observed 24 hours after the application of an orthodontic force, which is suggestive of bone resorption. ${ }^{39,40}$

\section{Transforming Growth Factor- $\beta 1$}

Transforming growth factor-beta1 (TGF- $\beta 1$ ) is a multifunctional cytokine that is involved in angiogenesis, immune suppression, extracellular matrix synthesis, apoptosis and cell growth inhibition. ${ }^{41}$ TGF- $\beta 1$ is one of the key cytokines with pleiotropic properties that has both proinflammatory and anti-inflammatory features in the regulation of the inflammatory infiltrate. This cytokine is a chemoattractant for neutrophils, monocytes, mast cells and lymphocytes. It also causes the release of proinflammatory cytokines, such as IL-1, IL- 6 and TNF- $\alpha$ by aforementioned cells. ${ }^{42}$

\section{Lactate Dehydrogenase}

Lactate dehydrogenase (LDH) is an enzyme that is normally limited to the cell cytoplasm and is released extracellularly, only after cell death. Studies have demonstrated a correlation between LDH activity in GCF and orthodontic tooth movement. ${ }^{43-45}$

\section{Matrix Metalloproteinases}

Matrix metalloproteinases (MMPs) are enzymes that play a central role in PDL remodeling both in physiological and pathological conditions. During orthodontic tooth movement, the collagenous extracellular matrix of the PDL and alveolar bone is remodeled. Bone resorption by osteoclasts involves demineralization of the bone inorganic matrix by acid and degradation of the bone organic matrix by cathepsin $\mathrm{K}$ and MMPs, although the precise role of MMPs in osteoclastic bone resorption is not fully understood. ${ }^{46,47}$ Collagenase-1 (MMP-1) and collagenase-2 (MMP-8) initiate this tissue remodeling due to their unique ability to cleave native triple-helical interstitial collagen. During orthodontic force application in dogs, MMP-1 gene expression was increased, and later decreased after force removal. ${ }^{48}$ However, the detection of MMP-1 in the GCF of patients undergoing orthodontic treatment was inconclusive. ${ }^{49}$

\section{Acid and Alkaline Phosphatase}

Monitoring acid and alkaline phosphatase (ALP) activity in tissues is a common way to assess bone turnover. Bone resorption induces elevations in acid phosphatase activity, whereas bone formation is associated with higher alkaline phosphatase activity. ${ }^{50}$ Typically, alkaline phosphatase will be elevated during early tooth movement, while the increase of acid phosphatase will accompany later stages of tooth movement. ${ }^{50}$

\section{Aspartate Aminotransferase}

Apoptosis releases aspartate aminotransferase (AST), a soluble enzyme, to the extracellular environment from the cytoplasm of cells. Therefore, elevated AST levels after 28 days in the GCF mirror the tissue destruction and bone remodeling processes that occur in the periodontium during controlled orthodontic tooth movement. ${ }^{51,52}$

\section{Cathepsin B}

Cathepsin B (CAB), an intracellular lysosomal cysteine proteinase, is a multifunctional biomarker that plays a key role in the initiation and continuation of inflammatory processes and is also involved in degrading extracellular components; including collagen and protein turnover in the lysosomal system. High levels of CAB in as early as 24 hours is reflective of the clinical inflammatory process during the primary stages of orthodontic treatment. ${ }^{53}$ The subsequent increment of $\mathrm{CAB}$ by 1 month post-treatment is indicative of the biological activity of decomposing the exposed collagen fiber and collagen degradation by-product. ${ }^{54}$

\section{$\beta$-Glucuronidase}

The lysosomal enzyme $\beta$-glucuronidase is a marker of primary granule release from neutrophils and takes part in the degradation process of connective tissue. A significant rise of $\beta$-glucuronidase after 2 weeks of orthodontic appliance activation has been observed. ${ }^{55}$

\section{Interleukin-1 Receptor Antagonist}

Interleukin-1 receptor antagonist (IL-1RA) is secreted by various types of immune cells and is a natural inhibitor of the proinflammatory effect of IL-1 $\beta$, thereby modulating IL-1 $\beta$-related immune and inflammatory responses to orthodontic forces. Interleukin-1 receptor antagonist is determined by decreased activity index (AI), which is the ratio of the concentration of IL- $1 \beta$ and IL-1RA in GCF. A lower value of IL-1RA is seen as a positive correlation between decreased gingival IL-1RA expression and faster orthodontic tooth movement. ${ }^{56,57}$ 


\section{Interferon $\gamma$}

Produced predominantly by T-cells, increased levels of interferon $\gamma$ (IFN- $\gamma$ ) play an important role in paradental remodeling. Periodontium remodeling during orthodontic tooth movement can be attributed to its immunoregulatory role and bone modeling through nitric oxide (NO) bone cell-activation, which is a potent stimulator of osteoclasts through its activation of RANKL and consequent induction of bone resorption. ${ }^{1,58}$

\section{Leptin}

Classified as a cytokine, leptin is a polypeptide hormone that plays a significant role in increased phagocytosis by macrophages in response to initial stress/strain created by orthodontic forces. This is followed by decreased levels of leptin in the GCF as a consequence of tissue resorption and likely cell necrosis in the PDL during orthodontic treatment. $^{59}$

\section{Insulin-like Growth Factor-1 and Insulin-like Growth Factor-Binding Protein 3}

Insulin-like growth factor-binding protein 3 (IGFBP-3) binds with insulin-like growth factor-1 (IGF-1). The IGF-1/ IGFBP-3 complex plays an important role in alveolar bone remodeling due to orthodontic forces. Decreased levels of IGFBP-3 secretion into GCF and altered molecular structures are observed due to orthodontic forces. However, these changes in IGFBP-3 show no association with the binding of IGF-I, indicative of an IGF-independent role of this binding protein in tooth movement. ${ }^{60}$

\section{Substance- $P$}

Substance-P is a neuropeptide that participates in the initial phase of orthodontic treatment by delivering and accumulating leukocytes to express a local immune response at the site of orthodontic forces. It is also involved in stimulating the bone resorption activity of osteoclasts and modulating the emotional stress experienced by the pain from the inserted appliance. Studies revealed a peak in production in the experimental sites one day after the insertion of the orthodontic appliance. ${ }^{61-63}$

\section{Pentraxin-3}

Pentraxin-3 (PTX3) is an acute-phase protein that is involved in the modulation of the aseptic inflammatory reaction. Therefore, during initial orthodontic treatment, its level rapidly increases and reaches its peak by 24 hours, after which it self-decreases. Thus, it can be a potential early biomarker in orthodontic tooth movement. ${ }^{64}$

\section{DISCUSSION}

Orthodontic forces trigger inflammatory process in the involved dental and periodontal tissues. Lymphocytes, monocytes and macrophages invade these tissues, enhancing the synthesis and release of various neurotransmitters, cytokines, growth factors, and metabolites of arachidonic acid, thus leading to increased osteoclastic activity. ${ }^{65}$ In orthodontics, the inflammatory process is a natural bridge toward solving functional and/or esthetic problems, as no tooth movement can be achieved without inflammation. However, orthodontically-induced inflammation and inflammatory mediators are transitory. Movement of teeth induced by orthodontic treatment involves reactions in the alveolar bone and in the PDL, gingiva, blood vessels and nerves. ${ }^{1}$ The bone remodeling that occurs during orthodontic tooth movement has been classically described as a continual and balanced process, characterized by bone deposition at sites of tension and bone resorption on the pressure side. Moreover, histomorphometric data have suggested that in both tension and compression sites, there may be an initial asynchronous phase in which bone resorption is greater than bone deposition. To date, few studies have focused on the GCF constituents involved in bone remodeling during orthodontic tooth movement.

The bone tissue reactions in response to orthodontic treatment are still elusive, and a detailed understanding of the biology of tooth movement and the outcome of treatment in individual patients is a complex process. The development of molecular biology along with translational studies in humans as well as in experimental systems are likely to provide much more detailed insight into the cellular and molecular mechanisms involved in the modeling processes induced by orthodontic forces. When bone is mechanically stimulated, the osteoclasts and their precursors are immediately activated to initiate resorption. ${ }^{66}$ Furthermore, osteoclast differentiation and recruitment are stimulated by hormones, cytokines, growth factors, and matrix components partly produced by osteoblasts. ${ }^{67}$

The biological response to orthodontic forces can be monitored by the analysis of various cell mediators and enzymes found in GCF. The induction of these markers comes from the compression of the PDL after the application of orthodontic force in levels sufficient enough to be diffused into the GCF. A number of GCF constituents have been studied in relation to the events that take place during orthodontic tooth movement. ${ }^{16,68}$ Markers, such as OC, TGF- $\beta$, ALP, TNF $\alpha, C A B$, epidermal growth factor, beta-2-microglobulin, glycosaminoglycans components, PGE2 as well as LDH activity and AST activity have been 
found to be significantly elevated in the GCF surrounding teeth undergoing orthodontic movement. $5,30,33,45,50,54,68-78$ The levels of interleukins in the GCF, especially those of IL-1 $\beta$, IL-8, IL-2 and IL-6 have been shown to increase during orthodontic treatment. ${ }^{72,79-82}$ The GCF level of MMPs and their inhibitors has been generally shown to peak at an average of 1 to 2 days after the application of the stimulus and return to baseline values after approximately 1 week. ${ }^{83-85}$ The role of RANKL and its inhibitor OPG in inducing alveolar bone remodeling during orthodontic tooth movement has been demonstrated. ${ }^{39,40,86}$

Based on the observations of various studies, it can be concluded that the analysis of GCF mediators reflects the biological activity that occurs in the periodontium during orthodontic tooth movement. However, due to the heterogeneity of the available studies, probably related to different GCF sampling and analysis procedures, it is difficult to draw a concrete conclusion. Thus, it is suggested that future studies should focus on the refinement of GCF sampling and measuring protocols, and the relationship between mediator production and force reactivation in order to provide a better illustration of the high potential of GCF as a diagnostic tool to monitor clinical outcome in orthodontics.

\section{CONCLUSION}

Studies have used GCF to assess changes within the periodontium and have related those changes to tooth movement. However, the majority of these studies have assessed individual biomarkers, which are representative of only a single biological pathway. Therefore, the assessment of a group of GCF biomarkers may provide better insight, and future research is encouraged to move in that direction.

\section{ACKNOWLEDGMENT}

The author would like to acknowledge Professor Anil Sukumaran and Dr Elna P Chalisserry for their assistance during the preparation of the manuscript.

\section{REFERENCES}

1. Krishnan V, Davidovitch Z. Cellular, molecular, and tissuelevel reactions to orthodontic force. Am J Orthod Dentofacial Orthop 2006;129(4):469.

2. Edwards JG. A long-term prospective evaluation of the circumferential supracrestal fiberotomy in alleviating orthodontic relapse. Am J Orthod Dentofacial Orthop 1988; 93(5):380-387.

3. Ingman $\mathrm{T}$, Apajalahti $\mathrm{S}$, Mantyla $\mathrm{P}$, Savolainen $\mathrm{P}$, Sorsa $\mathrm{T}$. Matrix metalloproteinase- 1 and -8 in gingival crevicular fluid during orthodontic tooth movement: a pilot study during 1 month of follow-up after fixed appliance activation. Eur J Orthod 2005;27(2):202-207.
4. Burke JC, Evans CA, Crosby TR, Mednieks MI. Expression of secretory proteins in oral fluid after orthodontic tooth movement. Am J Orthod Dentofacial Orthop 2002;121(3): 310-315.

5. Karacay S, Saygun I, Bengi AO, Serdar M. Tumor necrosis factor-alpha levels during two different canine distalization techniques. Angle Orthod 2007;77(1):142-147.

6. Holliday LS, Welgus HG, Hanna J, Lee BS, Lu M, Jeffrey JJ, Gluck Sl. Interstitial collagenase activity stimulates the formation of actin rings and ruffled membranes in mouse marrow osteoclasts. Calcif Tissue Int 2003;72(3):206-214.

7. Roberts WE, Huja S, Roberts JA. Bone modeling: biomechanics, molecular mechanisms, and clinical perspectives. Sem Orthod 2004;10(2):123-161.

8. Yamaguchi M. RANK/RANKL/OPG during orthodontic tooth movement. Orthod Craniofac Res 2009;12(2):113-119.

9. Delima AJ, Van Dyke TE. Origin and function of the cellular components in gingival crevice fluid. Periodontol 2003;31(1):55-76.

10. Cimasoni G. Crevicular fluid updated. Monogr Oral Sci 1983;12:III-VII.

11. Kowashi Y,Jaccard F, Cimasoni G. Sulcular polymorphonuclear leucocytes and gingival exudate during experimental gingivitis in man. J Periodontal Res 1980;15(2):151-158.

12. Meikle MC. The tissue, cellular, and molecular regulation of orthodontic tooth movement: 100 years after Carl Sandstedt. Eur J Orthod 2006;28(3):221-240.

13. Ren Y, Hazemeijer H, de Haan B, Qu N, de Vos P. Cytokine profiles in crevicular fluid during orthodontic tooth movement of short and long durations. J Periodontol 2007;78(3):453-458.

14. Ren Y, Maltha JC, Van't Hof MA, Von Den Hoff JW, KuijpersJagtman AM, Zhang D. Cytokine levels in crevicular fluid are less responsive to orthodontic force in adults than in juveniles. J Clin Periodontol 2002;29(8):757-762.

15. Miller SA, Forrest JL. Enhancing your practice through evidence-based decision making: PICO, learning how to ask good questions. J Evid Base Dent Pract 2001;1(2):136-141.

16. Ren $Y$, Vissink A. Cytokines in crevicular fluid and orthodontic tooth movement. Eur J Oral Sci 2008;116(2):89-97.

17. Rubin J, Ackert-Bicknell CL, Zhu L, Fan X, Murphy TC, Nanes MS, Marcus R, Holloway L, Beamer WG, Rosen CJ. IGF-I regulates osteoprotegerin (OPG) and receptor activator of nuclear factor-kappaB ligand in vitro and OPG in vivo. J Clin Endocrinol Metab 2002;87(9):4273-4279.

18. Garcia-Lopez S, Meikle MC, Villanueva RE, Montano L, Masso F, Ramirez-Amador V, Bojalil R. Mechanical deformation inhibits IL-10 and stimulates IL-12 production by mouse calvarial osteoblasts in vitro. Arch Oral Biol 2005;50(4): 449-452.

19. Iwasaki LR, Gibson CS, Crouch LD, Marx DB, Pandey JP, Nickel JC. Speed of tooth movement is related to stress and IL-1 gene polymorphisms. Am J Orthod Dentofacial Orthop 2006;130(6):e691-699.

20. Davidovitch Z, Nicolay OF, Ngan PW, Shanfeld JL. Neurotransmitters, cytokines, and the control of alveolar bone remodeling in orthodontics. Dent Clin North Am 1988; 32(3):411-435.

21. Alhashimi N, Frithiof L, Brudvik P, Bakhiet M. Orthodontic tooth movement and de novo synthesis of proinflammatory cytokines. Am J Orthod Dentofacial Orthop 2001;119(3):307-312. 
22. McCauley LK, Nohutcu RM. Mediators of periodontal osseous destruction and remodeling: principles and implications for diagnosis and therapy. J Periodontol 2002;73(11):1377-1391.

23. Guillot JL, Pollock SM, Johnson RB. Gingival interleukin-6 concentration following phase I therapy. J Periodontol 1995; 66(8):667-672.

24. Grieve WG, 3rd, Johnson GK, Moore RN, Reinhardt RA, DuBois LM. Prostaglandin E (PGE) and interleukin-1 beta (IL-1 beta) levels in gingival crevicular fluid during human orthodontic tooth movement. Am J Orthod Dentofacial Orthop 1994;105(4):369-374.

25. Ribagin LS, Rashkova MR. Matrix metalloproteinase- 8 and interleukin-1beta in gingival fluid of children in the first three months of orthodontic treatment with fixed appliances. Folia Med (Plovdiv) 2012;54(3):50-56.

26. Tzannetou S, Efstratiadis S, Nicolay O, Grbic J, Lamster I. Comparison of levels of inflammatory mediators IL-1 $\beta$ and $\beta G$ in gingival crevicular fluid from molars, premolars, and incisors during rapid palatal expansion. Am J Orthod Dentofacial Orthop 2008;133(5):699-707.

27. Aggarwal BB. Tumour necrosis factors receptor associated signalling molecules and their role in activation of apoptosis, JNK and NF-kappaB. Ann Rheum Dis 2000;59 Suppl 1:i6-16.

28. Ahuja SS, Zhao S, Bellido T, Plotkin LI, Jimenez F, Bonewald LF. CD40 ligand blocks apoptosis induced by tumor necrosis factor alpha, glucocorticoids, and etoposide in osteoblasts and the osteocyte-like cell line murine long bone osteocyte-Y4. Endocrinology 2003;144(5):1761-1769.

29. Seifi M, Eslami B, Saffar AS. The effect of prostaglandin E2 and calcium gluconate on orthodontic tooth movement and root resorption in rats. Eur J Orthod 2003;25(2):199-204.

30. Lee KJ, Park YC, Yu HS, Choi SH, Yoo YJ. Effects of continuous and interrupted orthodontic force on interleukin-1beta and prostaglandin E2 production in gingival crevicular fluid. Am J Orthod Dentofacial Orthop 2004;125(2):168-177.

31. Pender N, Samuels RH, Last KS. The monitoring of orthodontic tooth movement over a 2-year period by analysis of gingival crevicular fluid. Eur J Orthod 1994;16(6):511-520.

32. Last KS, Donkin C, Embery G. Glycosaminoglycans in human gingival crevicular fluid during orthodontic movement. Arch Oral Biol 1988;33(12):907-912.

33. Samuels RH, Pender N, Last KS. The effects of orthodontic tooth movement on the glycosaminoglycan components of gingival crevicular fluid. J Clin Periodontol 1993;20(5):371-377.

34. Kaku M, Motokawa M, Tohma Y, Tsuka N, Koseki H, Sunagawa H, Arturo Marquez Hernandes R, Ohtani J, Fujita T, Kawata T, et al. VEGF and M-CSF levels in periodontal tissue during tooth movement. Biomed Res 2008;29(4):181-187.

35. Knepper-Nicolai B, Reinstorf A, Hofinger I, Flade K, Wenz R, Pompe W. Influence of osteocalcin and collagen I on the mechanical and biological properties of Biocement D. Biomol Eng 2002;19(2-6):227-231.

36. Fassbender WJ, Steinhauer B, Stracke H, SchummDraeger PM, Usadel KH. Validation of a new automated immunoassay for measurement of intact osteocalcin. Clin Lab 2002;48(1-2):31-38.

37. Giannobile WV, Lynch SE, Denmark RG, Paquette DW, Fiorellini JP, Williams RC. Crevicular fluid osteocalcin and pyridinoline cross-linked carboxyterminal telopeptide of type I collagen (ICTP) as markers of rapid bone turnover in periodontitis. A pilot study in beagle dogs. J Clin Periodontol 1995;22(12):903-910.
38. Kobayashi Y, Takagi H, Sakai H, Hashimoto F, Mataki S, Kobayashi K, Kato Y. Effects of local administration of osteocalcin on experimental tooth movement. Angle Orthod 1998;68(3):259-266.

39. Nishijima Y, Yamaguchi M, Kojima T, Aihara N, Nakajima R, Kasai K. Levels of RANKL and OPG in gingival crevicular fluid during orthodontic tooth movement and effect of compression force on releases from periodontal ligament cells in vitro. Orthod Craniofac Res 2006;9(2):63-70.

40. Kawasaki K, Takahashi T, Yamaguchi M, Kasai K. Effects of aging on RANKL and OPG levels in gingival crevicular fluid during orthodontic tooth movement. Orthod Craniofac Res 2006;9(3):137-142.

41. Prime SS, Pring M, Davies M, Paterson IC. TGF-beta signal transduction in orofacial health and non-malignant disease (part I). Crit Rev Oral Biol Med 2004;15(6):324-336.

42. Marek A, Brodzicki J, Liberek A, Korzon M. TGF-beta (transforming growth factor-beta) in chronic inflammatory conditions-a new diagnostic and prognostic marker? Med Sci Monit 2002;8(7):RA145-151.

43. Perinetti G, Baccetti T, Contardo L, Di Lenarda R. Gingival crevicular fluid alkaline phosphatase activity as a noninvasive biomarker of skeletal maturation. Orthod Craniofac Res 2011;14(1):44-50.

44. Serra E, Perinetti G, D'Attilio M, Cordella C, Paolantonio M, Festa F, Spoto G. Lactate dehydrogenase activity in gingival crevicular fluid during orthodontic treatment. Am J Orthod Dentofacial Orthop 2003;124(2):206-211.

45. Alfaqeeh SA, Anil S. Lactate dehydrogenase activity in gingival crevicular fluid as a marker in orthodontic tooth movement. Open Dent J 2011;5:105-109.

46. Tsuji Y, Yamaza T, Kido MA, Goto T, Nakata S, Akamine A, Nakasima A, Tanaka T. Expression of cathepsin K mRNA and protein in odontoclasts after experimental tooth movement in the mouse maxilla by in situ hybridization and immunoelectron microscopy. Cell Tissue Res 2001;303(3):359-369.

47. Ohba Y,Ohba T, Terai K,Moriyama K. Expression of cathepsin K mRNA during experimental tooth movement in rat as revealed by in situ hybridization. Arch Oral Biol 2000;45(1):63-69.

48. Redlich M, Reichenberg E, Harari D, Zaks B, Shoshan S, Palmon A. The effect of mechanical force on mRNA levels of collagenase, collagen type I, and tissue inhibitors of metalloproteinases in gingivae of dogs. J Dent Res 2001; 80(12):2080-2084.

49. Apajalahti S, Sorsa T, Ingman T. Matrix metalloproteinase -2, $-8,-9$, and -13 in gingival crevicular fluid of short root anomaly patients. Eur J Orthod 2003;25(4):365-369.

50. Insoft M, King GJ, Keeling SD. The measurement of acid and alkaline phosphatase in gingival crevicular fluid during orthodontic tooth movement. Am J Orthod Dentofacial Orthop 1996;109(3):287-296.

51. Abdul Wahab RM, Abu Kasim N, Senafi S, Jemain AA, Zainol Abidin IZ, Shahidan MA, Zainal Ariffin SH. Enzyme activity profiles and ELISA analysis of biomarkers from human saliva and gingival crevicular fluid during orthodontic tooth movement using self-ligating brackets. Oral Health Dent Manag 2014;13(2):194-199.

52. Perinetti G, Paolantonio M, Serra E, D'Archivio D, D'Ercole S, Festa F, Spoto G. Longitudinal monitoring of subgingival colonization by Actinobacillus actinomycetemcomitans, and crevicular alkaline phosphatase and aspartate aminotransferase activities around orthodontically treated teeth. J Clin Periodontol 2004;31(1):60-67. 
53. Sugiyama Y, Yamaguchi M, Kanekawa M, Yoshii M, Nozoe T, Nogimura A, Kasai K. The level of cathepsin B in gingival crevicular fluid during human orthodontic tooth movement. Eur J Orthod 2003;25(1):71-76.

54. Rhee SH, Kang J, Nahm DS. Cystatins and cathepsin B during orthodontic tooth movement. Am J Orthod Dentofacial Orthop 2009;135(1):99-105.

55. Tzannetou S, Efstratiadis S, Nicolay O, Grbic J, Lamster I. Interleukin-1beta and beta-glucuronidase in gingival crevicular fluid from molars during rapid palatal expansion. Am J Orthod Dentofacial Orthop 1999;115(6):686-696.

56. IwasakiLR,CrouchLD, Tutor A, GibsonS,HukmaniN,MarxDB, Nickel JC. Tooth movement and cytokines in gingival crevicular fluid and whole blood in growing and adult subjects. Am J Orthod Dentofacial Orthop 2005;128(4):483-491.

57. Rody WJ Jr, Wijegunasinghe M, Wiltshire WA, Dufault B. Differences in the gingival crevicular fluid composition between adults and adolescents undergoing orthodontic treatment. Angle Orthod 2014;84(1):120-126.

58. Alhashimi N, Frithiof L, Brudvik P, Bakhiet M. Orthodontic movement induces high numbers of cells expressing IFNgamma at mRNA and protein levels. J Interferon Cytokine Res 2000;20(1):7-12.

59. Dilsiz A, Kilic N, Aydin T, Ates FN, Zihni M, Bulut C. Leptin levels in gingival crevicular fluid during orthodontic tooth movement. Angle Orthod 2010;80(3):504-508.

60. Toia M, Galazzo R, Maioli C, Granata R, Scarlatti F. The IGF-I/ IGFBP-3 system in gingival crevicular fluid and dependence on application of fixed force. J Endocrinol Invest 2005; 28(11):1009-1014.

61. Giannopoulou C, Dudic A, Kiliaridis S. Pain discomfort and crevicular fluid changes induced by orthodontic elastic separators in children. J Pain 2006;7(5):367-376.

62. Dudic A, Kiliaridis S, Mombelli A, Giannopoulou C. Composition changes in gingival crevicular fluid during orthodontic tooth movement: comparisons between tension and compression sides. Eur J Oral Sci 2006;114(5):416-422.

63. Yamaguchi M, Yoshii M, Kasai K. Relationship between substance $P$ and interleukin-1beta in gingival crevicular fluid during orthodontic tooth movement in adults. Eur J Orthod 2006;28(3):241-246.

64. Surlin P, Rauten AM, Silosi I, Foia L. Pentraxin-3 levels in gingival crevicular fluid during orthodontic tooth movement in young and adult patients. Angle Orthod 2012;82(5):833-838.

65. Mostafa YA, Weaks-Dybvig M, Osdoby P. Orchestration of tooth movement. Am J Orthod 1983;83(3):245-250.

66. Roodman GD. Cell biology of the osteoclast. Exp Hematol 1999;27(8):1229-1241.

67. Dolce C, Malone JS, Wheeler TT. Current concepts in the biology of orthodontic tooth movement. Sem Orthodon 2002;8(1):6-12.

68. Waddington RJ, Embery G. Proteoglycans and orthodontic tooth movement. J Orthod 2001;28(4):281-290.

69. Barbieri G, Solano P, Alarcon JA, Vernal R, Rios-Lugo J, Sanz M, Martin C. Biochemical markers of bone metabolism in gingival crevicular fluid during early orthodontic tooth movement. Angle Orthod 2013;83(1):63-69.

70. Uematsu S, Mogi M, Deguchi T. Increase of transforming growth factor-beta 1 in gingival crevicular fluid during human orthodontic tooth movement. Arch Oral Biol 1996;41(11): 1091-1095.

71. Perinetti G, Paolantonio M, D'Attilio M, D'Archivio D, Tripodi D, Femminella B, Festa F, Spoto G. Alkaline phosphatase activity in gingival crevicular fluid during human orthodontic tooth movement. Am J Orthod Dentofacial Orthop 2002;122(5):548-556.

72. Basaran G, Ozer T, Kaya FA, Kaplan A, Hamamci O. Interleukine-1beta and tumor necrosis factor-alpha levels in the human gingival sulcus during orthodontic treatment. Angle Orthod 2006;76(5):830-836.

73. Uematsu S, Mogi M, Deguchi T. Interleukin (IL)-1 beta, IL-6, tumor necrosis factor-alpha, epidermal growth factor, and beta 2-microglobulin levels are elevated in gingival crevicular fluid during human orthodontic tooth movement. J Dent Res 1996;75(1):562-567.

74. Kavadia-Tsatala S, Kaklamanos EG, Tsalikis L. Effects of orthodontic treatment on gingival crevicular fluid flow rate and composition: clinical implications and applications. Int J Adult Orthodon Orthognath Surg 2002;17(3):191-205.

75. Sari E, Kadioglu O, Ucar C, Altug HA. Prostaglandin E2 levels in gingival crevicular fluid during tooth- and bone-borne expansion. Eur J Orthod 2010;32(3):336-341.

76. Perinetti G, Serra E, Paolantonio M, Brue C, Meo SD, Filippi MR, Festa F, Spoto G. Lactate dehydrogenase activity in human gingival crevicular fluid during orthodontic treatment: a controlled, short-term longitudinal study. J Periodontol 2005;76(3):411-417.

77. Perinetti G, Paolantonio M, D'Attilio M, D'Archivio D, Dolci M, Femminella B, Festa F, Spoto G. Aspartate aminotransferase activity in gingival crevicular fluid during orthodontic treatment. A controlled short-term longitudinal study. J Periodontol 2003;74(2):145-152.

78. Wei FL, Wang CL, Liu DX, Guo J, Ke HF, Guo XX. Changes of aspartate aminotransferase and alkaline phosphatase activities in gingival crevicular fluid during rapid palatal expansion. Shanghai Kou Qiang Yi Xue 2007;16(2):168-171.

79. Celebi AA, Demirer S, Catalbas B, Arikan S. Effect of ovarian activity on orthodontic tooth movement and gingival crevicular fluid levels of interleukin-1beta and prostaglandin $\mathrm{E}(2)$ in cats. Angle Orthod 2013;83(1):70-75.

80. Luppanapornlarp S, Kajii TS, Surarit R, Lida J. Interleukin1beta levels, pain intensity, and tooth movement using two different magnitudes of continuous orthodontic force. Eur J Orthod 2010;32(5):596-601.

81. Tuncer BB, Ozmeric N, Tuncer C, Teoman I, Cakilci B, Yucel A, Alpar R, Baloş K. Levels of interleukin-8 during tooth movement. Angle Orthod 2005;75(4):631-636.

82. Basaran G, Ozer T, Kaya FA, Hamamci O. Interleukins 2, 6, and 8 levels in human gingival sulcus during orthodontic treatment. Am J Orthod Dentofacial Orthop 2006;130(1):7e1-6.

83. Bildt MM, Bloemen M, Kuijpers-Jagtman AM, Von den Hoff JW. Matrix metalloproteinases and tissue inhibitors of metalloproteinases in gingival crevicular fluid during orthodontic tooth movement. Eur J Orthod 2009;31(5):529-535.

84. Canavarro C, Teles RP, Capelli Junior J. Matrix metalloproteinases $-1,-2,-3,-7,-8,-12$, and -13 in gingival crevicular fluid during orthodontic tooth movement: a longitudinal randomized split-mouth study. Eur J Orthod 2013;35(5):652-658.

85. Capelli Jr J, Kantarci A, Haffajee A, Teles RP, Fidel R Jr, Figueredo CM. Matrix metalloproteinases and chemokines in the gingival crevicular fluid during orthodontic tooth movement. Eur J Orthod 2011;33(6):705-711.

86. Grant M, Wilson J, Rock P, Chapple I. Induction of cytokines, MMP9, TIMPs, RANKL and OPG during orthodontic tooth movement. Eur J Orthod 2013;35(5):644-651. 
87. Atug Ozcan SS, Ceylan I, Ozcan E, Kurt N, Dagsuyu IM, Canakci CF. Evaluation of oxidative stress biomarkers in patients with fixed orthodontic appliances. Dis Markers 2014;2014:597892.

88. Iwasaki LR, Chandler JR, Marx DB, Pandey JP, Nickel JC. IL-1 gene polymorphisms, secretion in gingival crevicular fluid, and speed of human orthodontic tooth movement. Orthod Craniofac Res 2009;12(2):129-140.

89. Iwasaki LR, Haack JE, Nickel JC, Reinhardt RA, Petro TM. Human interleukin-1 beta and interleukin-1 receptor antagonist secretion and velocity of tooth movement. Arch Oral Biol 2001;46(2):185-189.

90. van Gastel J, Teughels W, Quirynen M, Struyf S, Van Damme J, Coucke $\mathrm{W}$, et al. Longitudinal changes in gingival crevicular fluid after placement of fixed orthodontic appliances. Am J Orthod Dentofacial Orthop 2011;139(6):735-744.

91. Abdullah AAA, Wahab RMA, Ariffin SHbZ. Pattern of crevicular alkaline phosphatase during orthodontic tooth movement: leveling and alignment stage. Sains Malaysiana 2011;40(10):1147-1151.

92. Batra P, Kharbanda O, Duggal R, Singh N, Parkash H. Alkaline phosphatase activity in gingival crevicular fluid during canine retraction. Orthod Craniofac Res 2006;9(1):44-51.

93. Toygar HU, Kircelli BH, Bulut S, Sezgin N, Tasdelen B. Osteoprotegerin in gingival crevicular fluid under long-term continuous orthodontic force application. Angle Orthod 2008;78(6):988-993.

94. Kuroki H, Miyagawa Y, Shimomura-Kuroki J, Endo T, Shimomura H. Identification of marker proteins by orthodontic treatment: relationship of RANKL in the gingival crevicular fluid and of amylase in whole saliva with orthodontic treatment. Odontology 2014;102(2):303-309.

95. Alfaqeeh SA, Anil S. Osteocalcin and N-telopeptides of type I collagen marker levels in gingival crevicular fluid during different stages of orthodontic tooth movement. Am J Orthod Dentofacial Orthop 2011;139(6):e553-559. 